\title{
Knowledge, attitude and behavior of women towards abnormal menstrual bleeding and its impact on quality of life
}

\author{
Binti R. Bhatiyani*, Shrikant V. Dhumale, Pandeeswari B.
}

Department of Obstetrics and Gynecology, ESIPGIMSR Andheri, Mumbai, Maharashtra, India

Received: 16 August 2017

Accepted: 22 August 2017

\section{*Correspondence:}

Dr. Binti R. Bhatiyani,

E-mail: bintirlb@yahoo.co.in

Copyright: (C) the author(s), publisher and licensee Medip Academy. This is an open-access article distributed under the terms of the Creative Commons Attribution Non-Commercial License, which permits unrestricted non-commercial use, distribution, and reproduction in any medium, provided the original work is properly cited.

\begin{abstract}
Background: Abnormal menstrual bleeding has a major impact on a woman's quality of life. Any intervention therefore should aim to improve this rather than focusing on the amount of menstrual blood loss. The aim of this study was to gain an in depth understanding of women's current knowledge, attitudes and beliefs around abnormal menstrual bleeding. Also, to understand how it affects their lives, while identifying current misconceptions and gaps in knowledge and their expectations and attitudes towards the treatment so that treatment can address their most bothersome complaint.

Methods: A total of 200 women, between 18-55 years of age, not on any hormonal treatment attending the gynaecology OPD at a tertiary care centre between Jan 2017 to May 2017 were interviewed by a questionnaire. Women who had undergone hysterectomy were excluded from the study.

Results: Of the 200 women interviewed, 49 women felt that their bleeding was heavy and formed the heavy menstrual bleeding group (HMB) while 151 women who perceived their bleeding to be normal formed the normal bleeding group. In the (HMB) group, a significantly greater proportion of women identified their menstrual bleeding as being an inconvenience and a disruption to their lives. HMB also significantly affected their relationships, social life and productivity at work place.

Conclusions: Despite its common occurrence, awareness and understanding of HMB and its treatment within the survey population was poor.
\end{abstract}

Keywords: Menorrhagia, Menstrual flow, Quality of life

\section{INTRODUCTION}

Heavy menstrual bleeding is a common gynaecological condition. ${ }^{1}$ Traditionally research on HMB has objectively measured menstrual loss and labelled heavy bleeding as more than $80 \mathrm{ml}$ blood loss per cycle. ${ }^{2}$ Women's perception of what is normal regarding menstruation depends largely on their understanding of menstruation and what they perceive its function to be. ${ }^{3}$ It is difficult to measure menstrual blood loss objectively and the quantitative criteria do not take into account the quality of life which is significant. ${ }^{2,4}$ Abnormal bleeding could vary from irregular bleeding to heavy menstrual bleeding and it not only affects patients QoL but can also be a financial burden. ${ }^{2}$ It is important for health care professionals (HCP) to understand each woman's point of view to improve patient satisfaction. Recent research in the area of abnormal uterine bleeding has recognised the importance of 'patient experience' as an outcome that should be measured. ${ }^{5}$

For clinical purposes, Nice defines heavy menstrual bleeding as excessive menstrual blood loss which interferes with the woman's physical, emotional, social and material quality of life, and which can occur alone or in combination with other symptoms. Any interventions 
should aim therefore to improve quality of life measures. ${ }^{6}$ When measured quantitatively as blood loss more than 80 $\mathrm{ml}$, its prevalence has been found to range from 9 to $14 \%$, yet when measured qualitatively, its prevalence has been found as high as $52 \% .^{1,8}$ There is a lot of confusion regarding the nomenclature and potential causes of abnormal menstrual bleeding. Keeping this in mind FIGO FMDG group has now developed a new classification system for causes of abnormal uterine bleeding. ${ }^{9}$

A study by Matteson et al investigated whether the questions used by health care professionals (HCPs) to diagnose HMB adequately covered the aspects of women's lives that were impacted by this condition. ${ }^{6}$ This was done in conjunction with qualitative research to explore the effects that women felt HMB had on their lives. The results identified a number of areas not covered by standard HCP questioning, and recommended additional areas of questioning on which to focus. ${ }^{6}$ These areas included: time taken to soak through a large sanitary pad, frequency of rest room visits to check or change sanitary protection, frequency of passing blood clots. Despite providing useful information, this study investigated a small $(n=25)$ non-random sample, which limited the extent to which the study population could be considered representative and therefore, the ease with which the findings could be generalized. ${ }^{6}$

Other studies that have assessed the effect of HMB on QoL have found similar results in terms of the areas of women's lives that are affected which include social life, relationships and daily activities. ${ }^{10,11}$ Despite being informative, few studies have looked at these aspects in detail. Thus, there is a need to identify the knowledge gaps about how HMB affects women's lives so that the appropriate treatment and support can be offered.

\section{METHODS}

The objective of this study was to gain an in depth understanding of women's current knowledge, attitudes and beliefs pertaining to heavy menstrual bleeding (HMB). Also, to understand how it affects their lives, while identifying current misconceptions and gaps in knowledge and their expectations and attitudes towards the treatment so that treatment could address their most bothersome complaint.

The study population was recruited via a questionnaire to patients who presented to the OPD with various gynaecological complaints. Exclusion criteria were women who had undergone hysterectomy or were not willing to participate. Participants were women in the age group of 18-55 years, and were not currently taking HRT. Questions were designed to cover the following topic areas within $\mathrm{HMB}$

- Impact of HMB on QoL (Quality of life)

- Current awareness and knowledge of HMB
- Diagnosis and interaction with health care professionals in relation to HMB

- And awareness about the treatment modalities.

Abnormal menstrual bleeding was defined subjectively as bleeding which led to disruption of normal activities as per NICE. Majority of the women felt their bleeding was normal when the bleeding lasted for 4 to 5 days and they used 2 to 3 sanitary pads per day. The women who perceived their blood loss to be normal were grouped together in the normal bleeding group and those who perceived their bleeding to be heavy were grouped in the heavy menstrual group (HMB). Informed consent was taken from all women.

\section{Statistical analysis}

All the data was recorded on a specially prepared proforma and discrete categorical data was presented as n\%; Chi -square test and Fischers exact test was applied for comparison between the two groups of normal bleeding and abnormal bleeding. Statistical significance was set at $\mathrm{p}<0.05$

\section{RESULTS}

A total of 200 women met the eligibility criteria and went on to fully complete the questionnaire. All the women felt that it is important to have menses as it is a monthly cleaner and many of them said that decreased flow or absence of menses might lead to weight gain.

Out of the 200 women recruited, 49 felt their bleeding was above average and formed the heavy menstrual bleeding (HMB) group while 151 women perceived their bleeding to be normal and formed the normal menstrual bleeding group. The baseline characteristics were similar in the two groups. Majority were in the 20 to 40-year age group and had 2 to 4 children (Table 1).

When asked what bothers them the most, the response was varied in the normal and the heavy bleeding group. Majority of women in the heavy bleeding group quoted irregularity $(73.4 \%)$ and heaviness $(79.5 \%)$ as the most bothersome complaint. Other significant complaints were pain in $42 \%$ and mood changes. Whereas in the normal bleeding group majority quoted mood changes as the most bothersome compliant (35\%) (Table 2).

\section{Impact of HMB on QoL}

More women in the heavy menstrual flow group identified their menstrual cycle as being an inconvenience and disruption to their lives compared to those women with perceived normal menstrual flow.

In the heavy menstrual bleeding group, $83 \%$ of women stated that HMB impacted upon their daily activities. Further questioning showed that the impact of heavy menstrual bleeding stretched across multiple aspects of 
women's lives including social life, relationships and work. Significantly higher proportion of women $(81 \%)$ felt physically weak and unable to carry on day to day activities during days of heavy bleeding.

Table 1: Baseline data $(n=200)$. The baseline characteristics of the women in the two groups were comparable $i$. e. age, parity, BMI, educational level was comparable in the normal and abnormal bleeding. Majority of women were in 20 to 40-year group and had 2 to 4 children.

\begin{tabular}{|c|c|c|c|c|}
\hline & Normal bleeding group $(\mathrm{n}=\mathbf{1 5 1})$ & Abnormal bleeding ( $n=49)$ & Total 200 & $\begin{array}{l}\text { Chi square } \\
\text { (p value) }\end{array}$ \\
\hline \multicolumn{5}{|l|}{ Age } \\
\hline $21-30$ & $59(39 \%)$ & $12(24.4 \%)$ & $71(35.5 \%)$ & \multirow{4}{*}{$3.15(0.075)$} \\
\hline $31-40$ & $45(29.8 \%)$ & $16(32.6 \%)$ & $61(30.5 \%)$ & \\
\hline $41-50$ & $30(19.8 \%)$ & $14(28.5 \%)$ & $44(22 \%)$ & \\
\hline $51-60$ & $15(9.9 \%)$ & $9(18.3 \%)$ & $24(12 \%)$ & \\
\hline \multicolumn{5}{|l|}{ Parity } \\
\hline $0-2$ & $114(75.4 \%)$ & $35(71.4 \%)$ & $149(73 \%)$ & \multirow[t]{3}{*}{$0.32(0.57)$} \\
\hline $3-4$ & $35(23.1 \%)$ & $14(28.5 \%)$ & $49(24.5 \%)$ & \\
\hline 5 or more & $2(1.3 \%)$ & 0 & $2(1 \%)$ & \\
\hline \multicolumn{5}{|l|}{ Education } \\
\hline Illiterate & $18(11.9 \%)$ & $14(28.5 \%)$ & $32(16 \%)$ & \multirow[t]{5}{*}{ 7.6(0.0057) } \\
\hline Undermatric & $38(25.1 \%)$ & $14(28.5 \%)$ & $52(25.5 \%)$ & \\
\hline Matric & $41(27.1 \%)$ & $8(16.3 \%)$ & $49(24.5 \%)$ & \\
\hline Senior sec & $20(13.2 \%)$ & $3(6.1 \%)$ & $23(11.5 \%)$ & \\
\hline $\begin{array}{l}\text { Graduate and } \\
\text { above }\end{array}$ & $34(22.5 \%)$ & $10(20.4 \%)$ & $44(22 \%)$ & \\
\hline \multicolumn{5}{|l|}{ BMI } \\
\hline $18-25 \mathrm{~kg} / \mathrm{m} 2$ & $101(66.8 \%)$ & $31(63.2 \%)$ & $132(66 \%)$ & \multirow[t]{3}{*}{$0.16(0.68)$} \\
\hline $26-30$ & $41(27.1 \%)$ & $12(24.4 \%)$ & $53(26.5 \%)$ & \\
\hline$>30$ & $9(5.9 \%)$ & $6(12.2 \%)$ & $15(7.5 \%)$ & \\
\hline
\end{tabular}

Table 2: What bothers you the most?

\begin{tabular}{|c|c|c|c|c|}
\hline & $\begin{array}{l}\text { Normal bleeding group } \\
(\mathrm{n}=151)\end{array}$ & $\begin{array}{l}\text { Abnormal bleeding } \\
\text { group }(n=49)\end{array}$ & Total $(n=200)$ & Chi square ( $p$ value) \\
\hline Pain & $25(16.5 \%)$ & $21(42.8 \%)$ & $46(23 \%)$ & $23.93(<0.0001)$ \\
\hline Heaviness & $7(4.6 \%)$ & $39(79.5 \%)$ & $46(23 \%)$ & $117.3<0.0001$ \\
\hline Mood changes & $53(35 \%)$ & $18(36.7 \%)$ & $71(37.5 \%)$ & $7.4(0.0064)$ \\
\hline Irregularities & $5(3.3 \%)$ & $36(73.4 \%)$ & $41(20.5 \%)$ & $111.1(<0.0001)$ \\
\hline Breast pain & $9(5.9 \%)$ & $7(14.2 \%)$ & $16(8 \%)$ & $3.4(.06)$ \\
\hline Others & $67(44.3 \%)$ & $2(4 \%)$ & $69(34.5 \%)$ & $26.57(<0.0001)$ \\
\hline Nil complaints & $15(9.9 \%)$ & 0 & $15(7.5 \%)$ & \\
\hline
\end{tabular}

\section{Social life}

In the heavy menstrual bleeding group, $89 \%$ of women stated that they tend not to participate in social activities when their period is heavy.

A high proportion of women in this group also felt that their heaviest menstrual flow days impacted on the type and colour of the clothes they wore. They also felt less confident and less attractive during days of heavy flow. All values were significantly higher in the heavy menstrual bleeding group than normal bleeding group

\section{Relationships}

Significantly more women in the heavy menstrual bleeding group stated that their periods impacted on their relationships compared to women in the normal menstrual loss group.

A large proportion of these women stated that they avoided sexual activity when their period was heavy. $38 \%$ of women avoided sexual activity during heavy bleeding. They also felt that their heaviest flow days had an impact on their relationship with their partners. 
Table 3: Effect of menstrual bleeding on QoL.

\begin{tabular}{|c|c|c|c|c|}
\hline & $\begin{array}{l}\text { Normal } \\
\text { bleeding } n=151\end{array}$ & $\begin{array}{l}\text { Abnormal } \\
\text { bleeding } n=49\end{array}$ & $\begin{array}{l}\text { Total } \\
n=200\end{array}$ & Chi square \\
\hline Disruption in normal activities & $75(49.6 \%)$ & $41(83.6 \%)$ & $116(58 \%)$ & $17.56(\mathrm{p}<0.001)$ \\
\hline Limitation of work & $75(49.6 \%)$ & $39(79.5 \%)$ & $114(57 \%)$ & $13.51(\mathrm{P}<0.001)$ \\
\hline Skip social activities & $74(49 \%)$ & $44(89.7 \%)$ & $118(59 \%)$ & $25.44(\mathrm{p}<0.001)$ \\
\hline Avoid travel & $75(49.6 \%)$ & $46(93.8 \%)$ & $121(60.5 \%)$ & $30.25(\mathrm{p}<0.001)$ \\
\hline Avoids family/friends/get together & $67(44.3 \%)$ & $39(79.5 \%)$ & $106(53 \%)$ & $18.42(\mathrm{p}<0.001)$ \\
\hline Isolation at home & $45(29.8 \%)$ & $29(59.1 \%)$ & $74(37 \%)$ & $13.7(\mathrm{p}<0.001)$ \\
\hline Change in colour and type of clothes & $60(39.7 \%)$ & $32(65.3 \%)$ & $92(46 \%)$ & $9.29(\mathrm{p}<0.002)$ \\
\hline Change in the type of under wear & $70(46.3 \%)$ & $34(69.3 \%)$ & $104(52 \%)$ & $5.7(\mathrm{p}<0.016)$ \\
\hline Feeling less confident or attractive & $45(29.8 \%)$ & $25(51 \%)$ & $70(35 \%)$ & $7.3(\mathrm{p}<0.006)$ \\
\hline Feeling physically weak & $75(49.6 \%)$ & $40(81.6 \%)$ & $115(57.5 \%)$ & $15.4(\mathrm{p}<0.001)$ \\
\hline Mood changes & $45(29.8 \%)$ & $29(59.1 \%)$ & $74(37 \%)$ & $13.7(\mathrm{P}<0.001)$ \\
\hline Myths related/religious beliefs & $72(47.6 \%)$ & $20(40.8 \%)$ & $92(46 \%)$ & $0.7(\mathrm{p} 0.4)$ \\
\hline Avoid sexual activity during periods & $23(15.2 \%)$ & $19(38.7 \%)$ & $42(21 \%)$ & $20.18(\mathrm{p}<0.001)$ \\
\hline $\begin{array}{l}\text { Whether they feel shy discussing with health } \\
\text { care professional }\end{array}$ & $45(29.8 \%)$ & $19(38.7 \%)$ & $64(32 \%)$ & $1.3(\mathrm{p} 0.24)$ \\
\hline
\end{tabular}

\section{Work}

Heavy menstrual bleeding has an impact on productivity with $79.5 \%$ of women in the HMB group stating that heavy bleeding affected their performance at work. The proportion of women who felt that heavy bleeding affected their work was significantly higher in the HMB group. Outside of work majority preferred to avoid travel on days of heavy bleeding

\section{Management of $A U B$}

Women affected by HMB often adapt life style changes in order to manage their condition. In this study on enquiry, $65 \%$ women in the heavy bleeding group answered that on heavy days they would avoid certain colours or clothes to cope with the bleeding. In terms of social life $79.5 \%$ of women in the heavy bleeding said they avoided family gatherings.

\section{Awareness and knowledge of $A U B$}

Despite being a common condition the awareness among the women about the condition and its treatment was low (Table 4). There was no significant difference in both the groups regarding the awareness level. Majority correlated heavy bleeding with malignancy and felt that heavy bleeding is something serious and needs to be treated. Even the women who had awareness about the condition, the awareness about the treatment options was poor.

Table 4: Knowledge regarding abnormal menstrual bleeding ( $n=200)$. Knowledge of women about abnormal bleeding, its treatment and consequences.

\begin{tabular}{|c|c|c|c|c|}
\hline & $\begin{array}{l}\text { Normal bleeding } \\
(\mathbf{n}=\mathbf{1 5 1})\end{array}$ & $\begin{array}{l}\text { Abnormal bleeding } \\
(\mathrm{n}=49)\end{array}$ & $\begin{array}{l}\text { Total } \\
(n=200)\end{array}$ & $\begin{array}{l}\text { Chi square } \\
\text { p value }\end{array}$ \\
\hline Are they aware of AMB & $135(89.4 \%)$ & $46(93.8 \%)$ & $181(90.5 \%)$ & $0.861(0.35)$ \\
\hline Knowledge about treatment options available & $33(21.8 \%)$ & $14(28.5 \%)$ & $47(23.5 \%)$ & $0.928(0.33)$ \\
\hline $\begin{array}{l}\text { Knowledge about association with } \\
\text { malignancies }\end{array}$ & $68(45 \%)$ & $29(59.1 \%)$ & $97(48.5 \%)$ & $2.96(0.08)$ \\
\hline Knowledge about consequences of HMB & $12(7.9 \%)$ & $10(20.4 \%)$ & $22(11 \%)$ & $5.8(0.015)$ \\
\hline $\begin{array}{l}\text { Do they think HMB is something serious and } \\
\text { needs to be treated }\end{array}$ & $134(88.7 \%)$ & $48(97.9 \%)$ & $182(91 \%)$ & $3.8(0.05)$ \\
\hline
\end{tabular}

\section{DISCUSSION}

This study supports the findings of previous research showing heavy menstrual bleeding to be a common problem which can impact on many aspects of a woman's life including social, relationships and work. ${ }^{4,6,13}$ The patient centric approach is reflected in the definition of heavy menstrual bleeding by Nice which takes into 
account the woman's perceptions of menstrual blood loss and the subsequent impact on their quality of life. ${ }^{7}$

The results from this study show that significantly more women in the heavy bleeding group identified their bleeding to be problematic than the normal bleeding group. In a study by Bitzer et al, a total of 6179 women, 18 to 55 years of age, open to using hormonal contraception were studied regarding their perception of HMB and its impact on Qol. Of the women who perceived themselves as having HMB flow, a significantly greater proportion identified their menstrual bleeding as problematic compared to women who perceived having normal menstrual flow.

The diagnosis of HMB extended to multiple aspects of the women's lives, including social life, relationships and work with a significantly greater proportion of women reporting negative effects in these domains in the HMB group. ${ }^{4}$ So patient centric understanding of the complaint may lead to better understanding of patient's illnesses and can contribute to improved patient satisfaction with the results of treatment. ${ }^{4}$

When asked about their awareness regarding heavy menstrual bleeding majority of the women $(93.8 \%)$ in this study were aware about abnormal bleeding but as such they were not knowledgable about the treatment available and the consequences of AMB. There was no significant difference in both groups regarding their awareness level. This is similar to the study done by Harpreet kaur et al. ${ }^{12}$

Also, in the multicentre study by Bizer et al, awareness among the survey participants was low. ${ }^{4}$ When the global study population was asked if they had heard of HMB, $34 \%$ of them answered no or do not know. Even in the awareness group, understanding of abnormal bleeding and available treatment options was lacking. ${ }^{4}$

Esmai et al conducted a cross sectional survey of 400 college students to assess their awareness about menstrual abnormalities and health seeking behaviour. Students awareness of menstrual abnormalities was poor (29\%).Only a few of them $(10.5 \%)$ decided to seek help for menstrual abnormalities. ${ }^{13}$ Due to myths attached to menstruation as something unhygienic, many a times heavy menstrual bleeding may go undiagnosed and untreated leading to an unnecessary suffering in women. ${ }^{2}$

\section{CONCLUSION}

Thus, such studies reinforce the need to consider woman's perception of menstrual blood loss and its effect on QoL while deciding her care. There is a need to raise awareness among women about abnormal menstrual bleeding and its treatment options.
In order to improve patient satisfaction with her care it is important that the areas which are most bothersome be addressed.

\section{ACKNOWLEDGMENTS}

Authors would like to thank our Dean Dr. Meenakshi Mathur for her guidance and support.

Funding: No funding sources

Conflict of interest: None declared

Ethical approval: The study was approved by the Institutional Ethics Committee

\section{REFERENCES}

1. Fraser IS, Langham S, Uhl-Hochgraeber K. Healthrelated quality of life and economic burden of abnormal uterine bleeding. Expert Rev Obstet Gynecol. 2009;4(2):179-89.

2. Hallberg L, Högdahl AM, Nilsson L, Rybo G. Menstrual blood loss-a population study. Variation at different ages and attempts to define normality. Acta Obstet Gynecol Scand. 1966;45(3):320-51.

3. Coutinho EM, Segal SJ. Is Menstruation Obsolete? New York: Oxford University Press; 1999

4. Bitzer J, Serrani M, Lahav A. Womens attitudes towards heavy menstrual bleeding and their impact on quality of life. Open Access J Contraception. 2013;4:21-8.

5. Clark TJ, Khan KS, Foon R, Pattison H, Bryan S, Gupta JK. Quality of life instruments in studies of menorrhagia: a systematic review. Eur J Obstet Gynecol Reprod Biol. 2002;104:96-1045.

6. Matteson K A, Clark MA. Questioning our questions: do frequently asked questions adequately cover the aspects of womens lives most affected by abnormal uterine bleeding? Opinions of women with abnormal uterine bleeding participating in focus group discussions. Women Health. 2010;50(2):195211

7. National Collaborating Centre for Womens and Childrens Health. Heavy menstrual bleeding. Dorchester: RCOG;2007. Available at :http://www.nice.org.uk/nicemedia/live/11002/30401 130401.pdf.Accessed online on August 13,2012.

8. Shapley M. Jordan K, Croft PR. An epidemiological survey of symptoms of menstrual loss in the community. Br J Gen Pract. 2004;54(502):359-363.

9. Munro MG, Critchley, Fraser IS. The FIGO Menstrual Disorders Working Group. The FIGO classification of causes of abnormal uterine bleeding in the reproductive years. Fertil Steril. 2011;95(7):2204-220.

10. Santer M, Wyke S, Warner P. What aspects of periods are most bothersome for women reporting heavy menstrual bleeding? Community survey and qualitative study. BMC Womens Health. 2007;7:8. 
11. O’Flynn N, Britten N. Menorrhagia in general practice-disease or illness. Soc Sci Med. 2000;50(5):651-61.

12. Kaur H, Sharma S, Goraya SPS. Knowledge ,Attitude and Behaviour of women towards Abnormal Menstrual Bleeding and its impact on Quality of Life. J South Asian Feder Obst Gynaec. 2015;7(1):5-9.

13. Esimai OA, Esan GOO. Awareness of menstrual abnormality among college students in urban area of
Ilea-Ife, Osun State, Nigeria. Ind J Community Med. 2010;35(1):63-6.

Cite this article as: Bhatiyani BR, Dhumale SV, Pandeeswari B. Knowledge, attitude and behaviour of women towards abnormal menstrual bleeding and its impact on quality of life. Int J Reprod Contracept Obstet Gynecol 2017;6:4291-6. 